\title{
MÃOS QUE CURAM
}

\author{
JULIANA Nicolle BARRETO
}

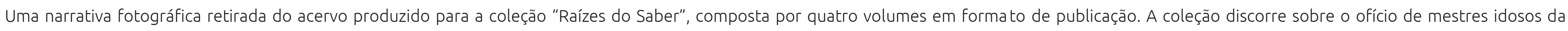
cultura Agrestina de Alagoas, focalizando quatro seguimentos: Parteiras, Gastronomia Popular, Terapeutas Tradicionais e Produção Artesanal.

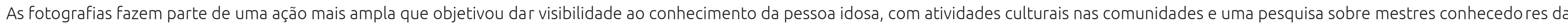

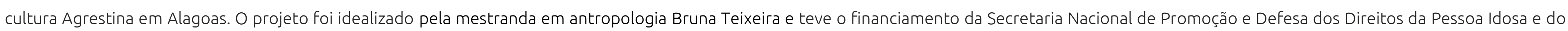
Ministério dos Direitos Humanos.

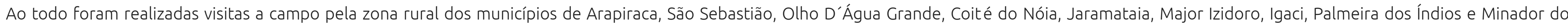
Negrão, todos localizados no Agreste e bacia leiteira de Alagoas. As fotografias foram registradas a título de ilustração para a publicação da pesquisa anteriormente realizada.

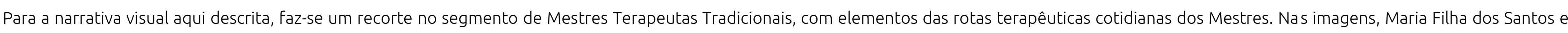
Jurinete Pereira, de Arapiraca; Alice Hermenegilda da Conceição, Coité do Nóia, parteira e rezadeira; e Olavo da França Silva, rezador de Palmeira dos Índios. 

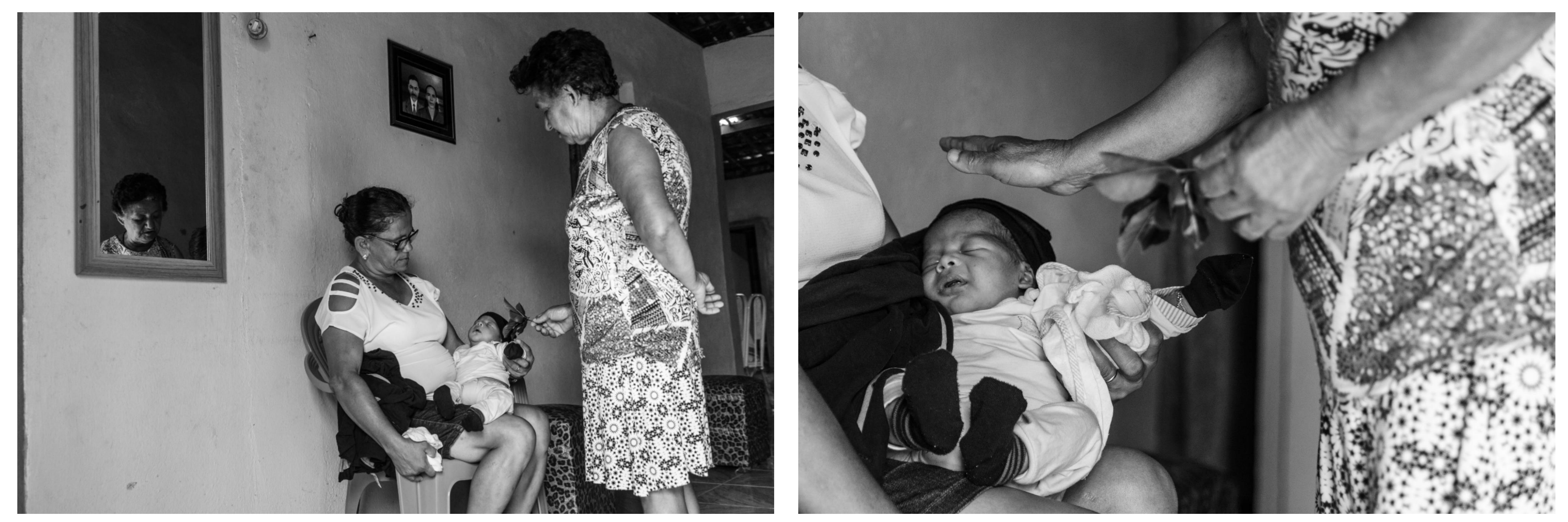

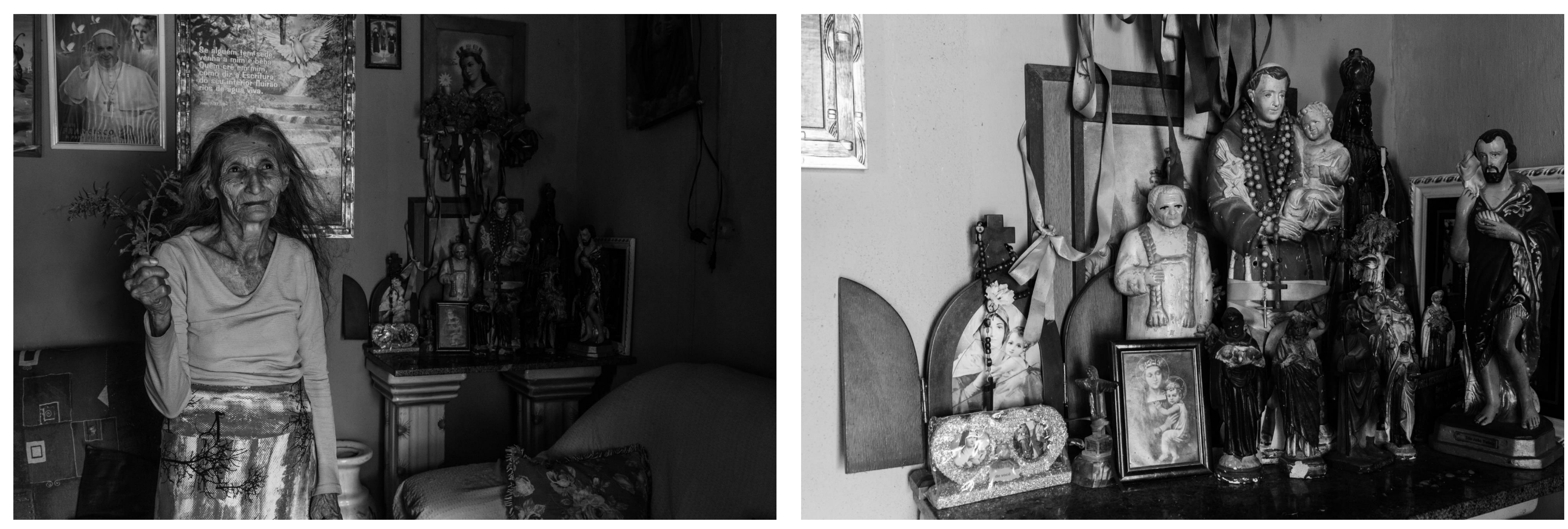

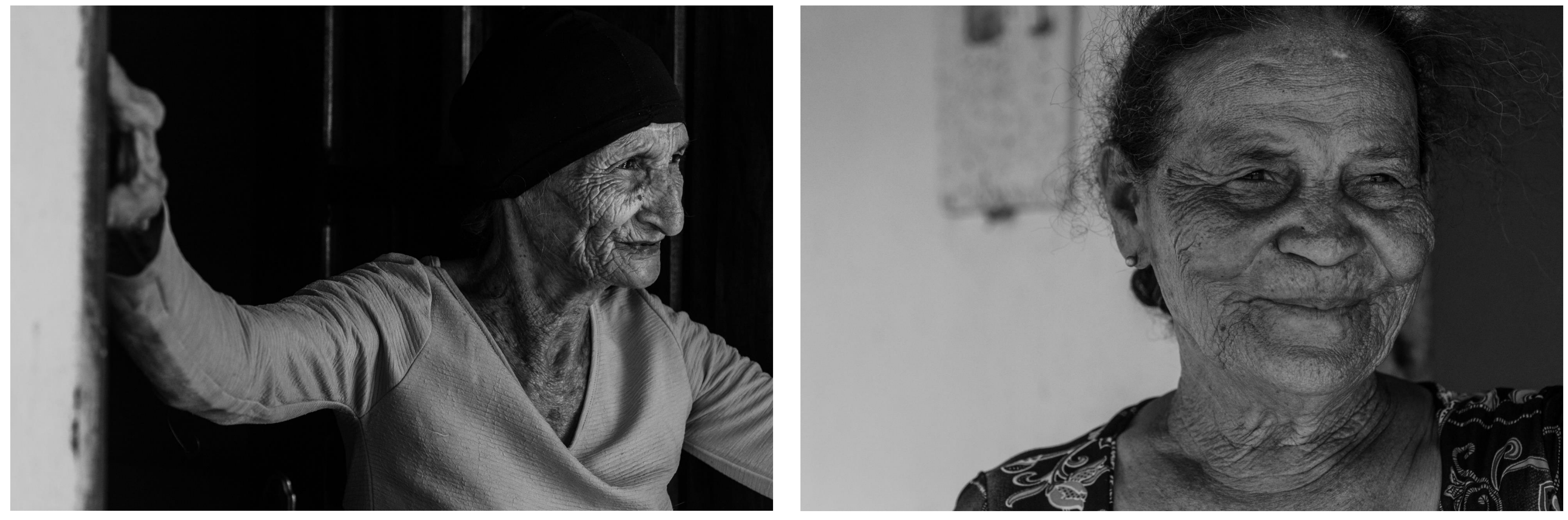

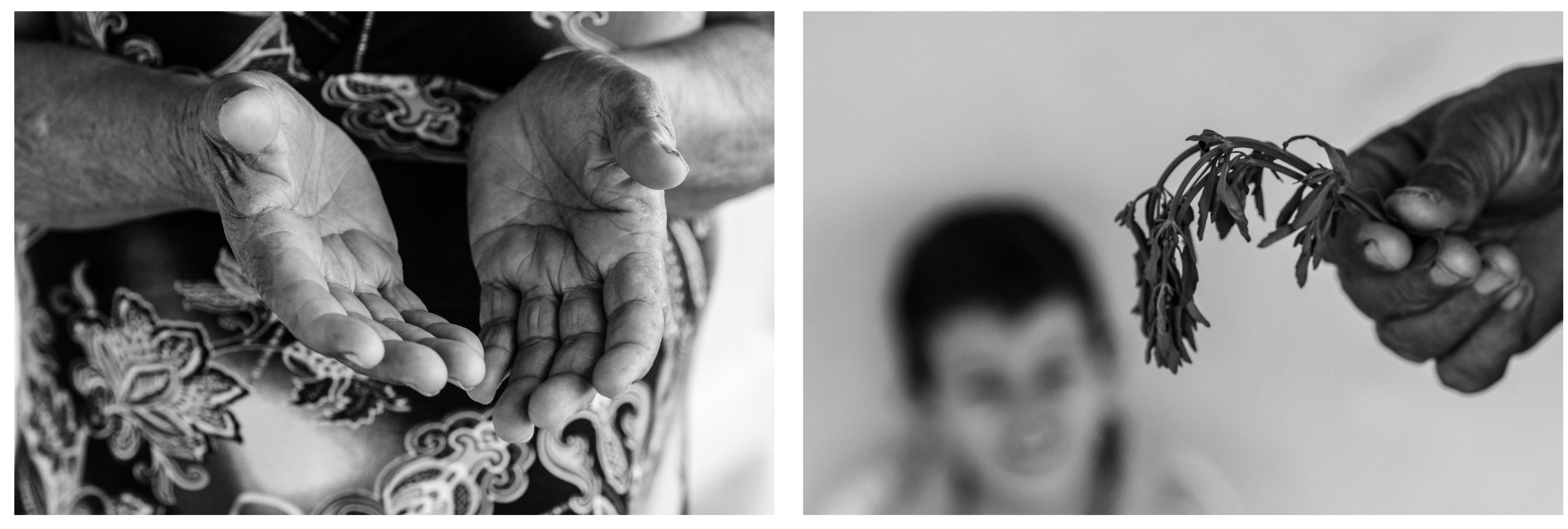

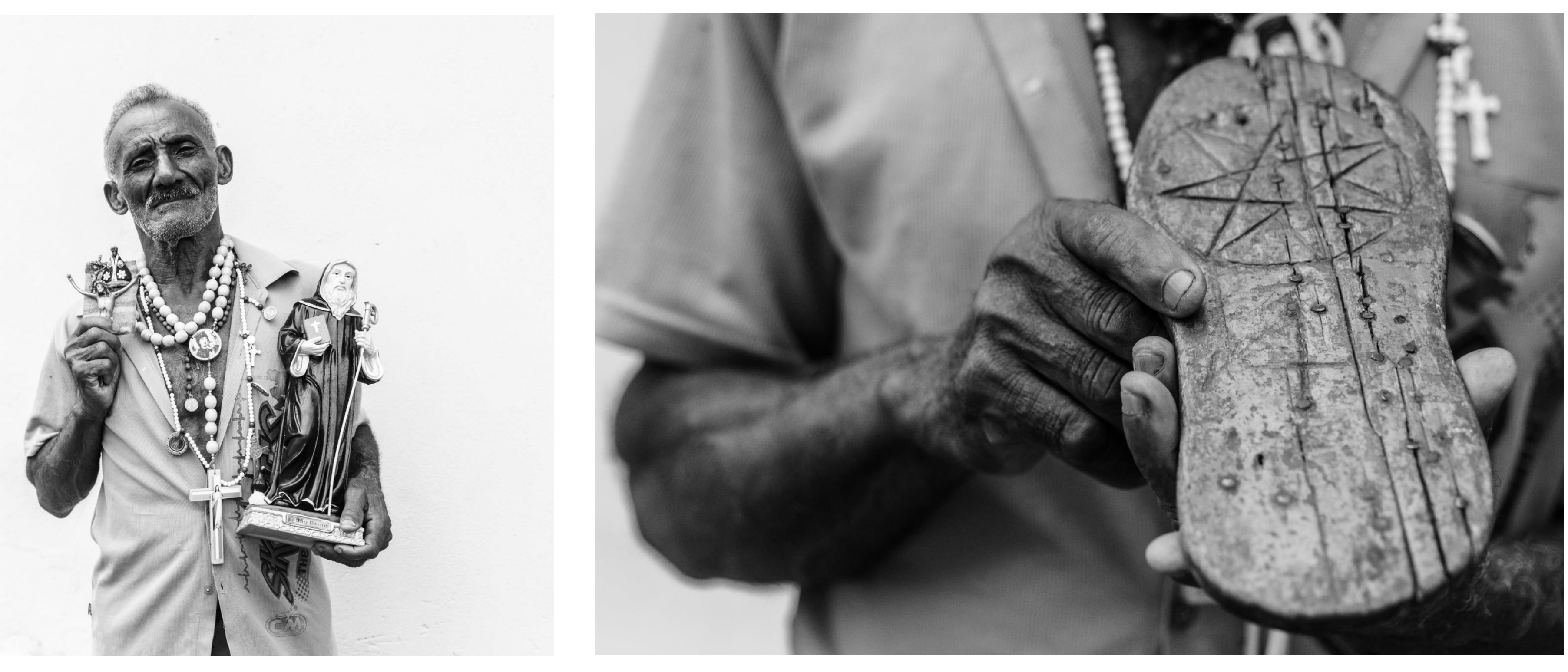


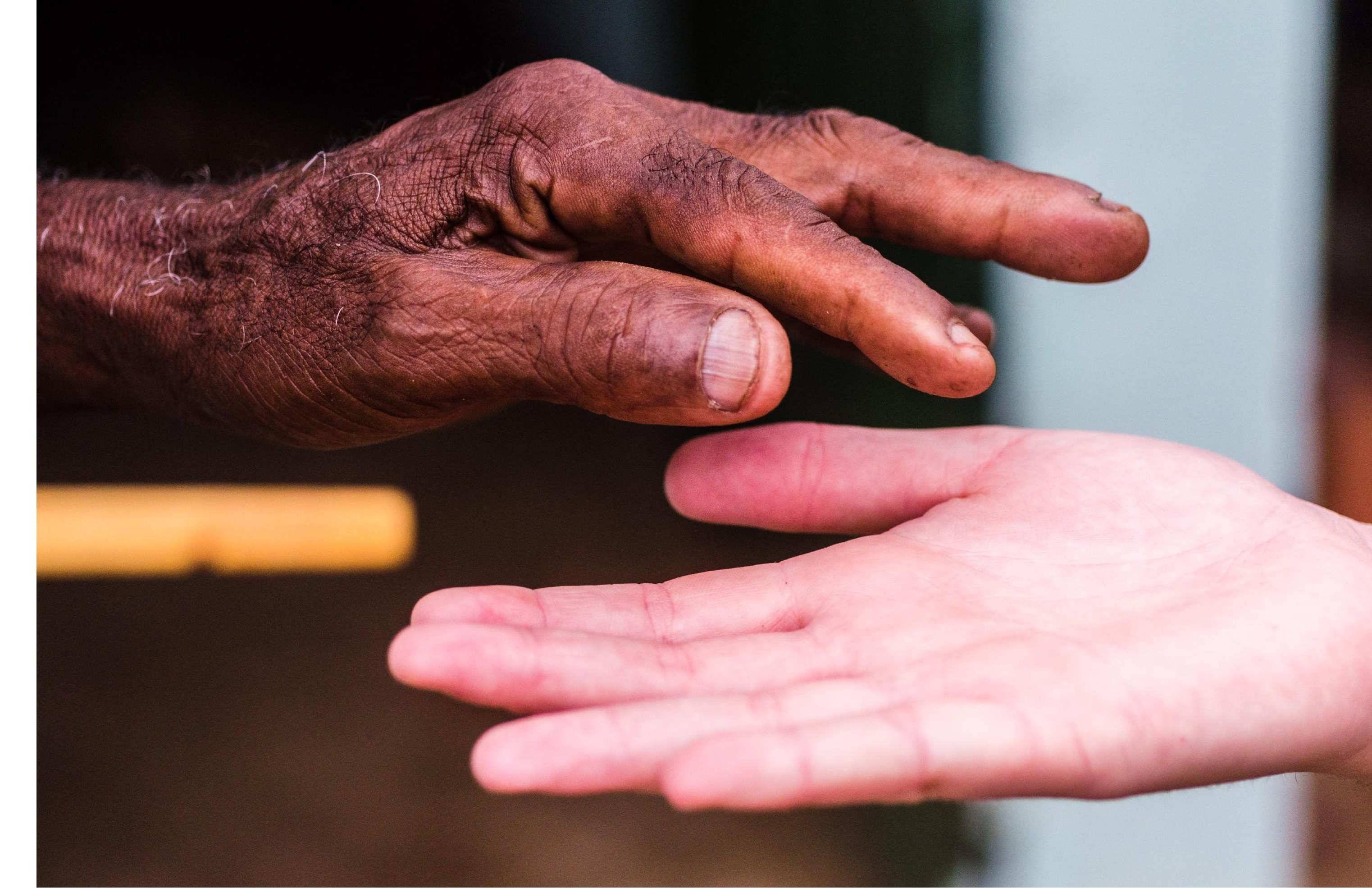


TEIXEIRA, Bruna; RAMALhO, Ayodhya (coord). “Parteiras”. Projeto Raízes do Saber, Maceió, ITV, (Raízes do Saber, 1), 2018. TEIXEIRA, Bruna; RAMALhO, Ayodhya (coord). “Terapeutas Tradicionais". Projeto Raízes do Saber, Maceió, ITV, (Raízes do Saber, 2), 2018. TeIXEIRA, Bruna; RAMALHO, Ayodhya (coord). "Chefes da Gastronomia Popular". Projeto Raízes do Saber, Maceió, ITV, (Raízes do Saber, 3),2018. TEIXEIRA, Bruna; RAMALHO, Ayodhya (coord). “Mestres e Mestras da Produção Artesanal”. Projeto Raízes do Saber, Maceió, ITV, (Raízes do Saber, 4), 2018.

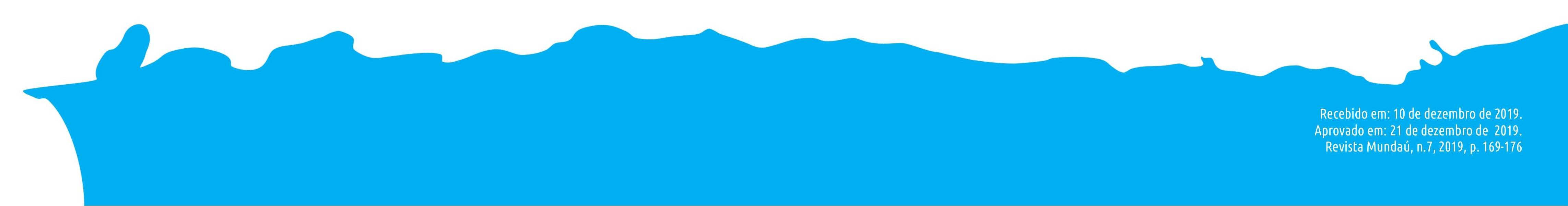

